\title{
MENTAL STRESS MANAGEMENT BASED ON AUDIO-VISUAL MEDIA
}

\section{(Manajemen Stres Berbasis Media Audio Visual)}

\author{
Maria Frani Ayu A.D, Heri Kristianto \\ STIKES Suaka Insan Banjarmasin \\ Program Studi Ilmu Keperawatan Fakultas Kedokteran Universitas Brawijaya \\ E-mail: nersmary0145@gmail.com
}

\begin{abstract}
ABSTRAK
Pendahuluan. Saat ini pengembangan metode pembelajaran dalam pendidikan keperawatan semakin bervariasi. Hal ini juga didukung oleh peningkatan pemanfaatan teknologi informasi dan komunikasi. Penelitian ini bertujuan untuk mengembangkan media pembelajaran asuhan keperawatan jiwa manajemen stress dengan berbasis pada media audio visual dalam bentuk video dengan memanfaatkan program Camtasia studio 8.4. Metode. Proses perancangan media dilakukan dengan menggunakan 6 tahap yaitu, tahap konsep, perancangan, pengumpulan materi, pembuatan, pengujian dan distribusi. Hasil. Hasil pengembangan media pembelajaran berupa video, menunjukkan bahwa video ini dapat digunakan sebagai salah satu metode pembelajaran yang diterapkan dan diajarkan saat kegiatan perkuliahan. Diskusi. Pengembang dapat menggunakan rancangan ini sebagai dasar pengembangan media pembelajaran berbasis audio-visual dengan menambahkan beberapa komponen materi seperti yang telah disarankan oleh para komentator-komentator sebelumnya.
\end{abstract}

Kata kunci: Media pembelajaran, audio visual, camtasia

\begin{abstract}
Background. Currently the development of teaching methods in nursing education more varied. It is also supported by the increased use of information and communication technology. This research aimed to develop learning media nursing care mental stress management based on audio-visual media in the form of video to utilize the program Camtasia Studio 8.4. Method. Media design process was done by using the 6 phases, stages of concept, design, collection of material, manufacture, testing and distribution. Result. The results of the development of instructional media such as video, showing that this video can be used as a learning method was applied and taught when learning activities. Discussion. Developers can use this design as the basis for the development of media-based learning audio-visual material by adding a few components as has been suggested by previous commentators.
\end{abstract}

Keywords: Learning media, audio visual, camtasia

\section{PENDAHULUAN}

Peningkatan mutu pendidikan merupakan salah satu unsur konkrit yang sangat penting dalam upaya peningkatan kualitas sumber daya manusia. Pendidikan Keperawatan jiwa saat ini berkembang dengan pesat baik dari segi pelayanan dan pendidikan. Dalam bidang pendidikan keperawatan jiwa, metode tradisional seperti role play, skenario kasus, sampai saat ini masih efektif digunakan untuk mengajarkan ilmu keperawatan jiwa (Brunero, Jeon, \& Foster, 2012). Meskipun demikian, saat ini sudah dikembangkan pembelajaran multimedia yang oleh Lamont and Brunero (2012) dikembangkan dalam 'eSimulation' untuk pembelajaran keperawatan jiwa umum dengan sasaran para Perawat. eSmulation merupakan produk simulasi yang menampilkan kenyataan, dan pembelajaran aktif oleh pengguna dengan menggunakan perangkat komputer (Billings \& Halstead, 2005). Selain dalam bentuk simulasi, ditemukan pula media pembelajaran sederhana yang berbentuk audio-visual (Avs) dalam mempelajari ilmu keperawatan seperti penggunaan You tube dan aplikasi Web 2.0 lainnya seperti "facebook", "Myspace" (Hansen \& Erdley, 2009). Youtube disini digunakan sebagai sarana untuk belajar dalam bentuk media pembelajaran audio visual jenis video.

Pengembangan perangkat ini didasarkan dari komitmen MHEPs (Mental Health education program) atau semacam sebuah lembaga pengembangan keilmuan pendidikan kejiwaan di Australia, untuk mengembangkan pengetahuan, keterampilan dan sikap serta pemberian asuhan yang 
profesional oleh petugas kesehatan (Brunero et al., 2012). MHEPs juga telah bekerja dalam menggerakkan berbagai macam penelitian di bidang multimedia untuk mengembangkan asuhan keperawatan jiwa kepada pasien serta mengembangkan berbagai macam produk pembelajaran yang sangat menarik.

Di Indonesia sendiri, jarang ditemukan penelitian dan catatan yang mengarah pada pengembangan simulasi belajar dalam bentuk audio-visual seperti yang diuraikan di atas. Namun, sudah mulai banyak ditemukan penelitian-penelitian dengan mengembangkan produk audio-visual dalam memberikan asuhan keperawatan, seperti penelitian Hermaningsih and Nargis (2010) dengan menggunakan video yang dikombinasikan dengan leaflet dalam upaya meningkatkan perilaku perawatan diri remaja. Media pembelajaran dalam bentuk audio visual dengan jenis video dinilai sebagai alat belajar yang sangat kuat karena sifatnya yang dapat diulang dan menampilkan gambar gerak dan suara yang nyata (Hansen \& Erdley, 2009).

Selanjutnya adalah penelitian Mubin (2013) terkait dengan perancangan media pembelajaran interaktif sistem skeletal pada mata kuliah dasar keperawatan I. Perancangan media menggunakan animasi dan Macromedia flash 8. Hasil penelitian menunjukkan ketertarikan dan antusiasme dari mahasiswa keperawatan. Namun, sejauh ini tidak ditemukan catatan yang menunjukkan perancangan media pembelajaran untuk asuhan keperawatan jiwa.

Asuhan keperawatan jiwa adalah materi ajar yang diberikan kepada mahasiswa keperawatan pada saat ia menjalani pendidikan keperawatan di bangku kuliah. Sumber materi ini adalah lebih banyak berupa buku teks. Dalam mempelajarinya, mahasiswa akan dihadapkan pada beberapa simulasi atau praktik yang harus dikerjakan untuk memahami keadaan pasien dan asuhan yang harus diberikan kepada pasien tersebut (Townsend, 2011). Berdasarkan paparan fakta-fakta penelitian di atas, tidak salahnya menggunakan metode dan media belajar lain untuk memperoleh ilmu. Sehingga, disusunlah sebuah rancangan media pembelajaran yang diharapkan dapat memberikan warna baru bagi pembelajaran keperawatan jiwa pada mahasiswa/i keperawatan yang menarik, menyenangkan dan mudah dipahami.

Manajemen stress dipilih sebagai topik bahasan dalam rancangan media pembelajaran ini. Hal ini dikarenakan stress adalah keadaan yang terjadi pada semua orang (Townsend, 2011). Diharapkan, karena sifatnya ini, topik ini dapat memberikan kemudahan kepada mahasiswa/i serta masyarakat dalam memahami setiap proses-proses di dalamnya.

\section{METODE}

Penelitian ini merupakan penelitian pengembangan dengan model pengembangan multimedia menurut Luther dalam Binanto (2010). Model tersebut terbagi menjadi beberapa tahap yaitu, tahap konsep, perancangan, pengumpulan materi, pembuatan, pengujian dan pendistibusian. Tahapan-tahapan ini digambarkan sebagai berikut:

1. Konsep

Konsep untuk media pembelajaran ini adalah berbasis audiovisual dalam bentuk video pembelajaran yang sederhana dan menarik bagi mahasiswa/i keperawatan dan masyarakat awam. Topik dari media pembelajaran adalah berupa Manajemen stress. Alasan pemilihan topik ini adalah karena stress adalah hal yang terjadi pada semua orang, semua orang merasakannya dan memiliki cara berbeda-beda untuk menghadapinya.

2. Perancangan

Perancangan dalam penelitian ini dilakukan dengan membuat sistem pakar untuk media pembelajaran yang sesuai dengan topik yang telah disepakati.

3. Pengumpulan materi

Pengumpulan materi dilakukan dengan Penelitian dan pengumpulan data terkait stress yang dilanjutkan dengan menelusuri manajemen atau cara penanganannya. Materi didapatkan dari buku pegangan asuhan keperawatan jiwa Townsend (2011) dan beberapa hasil wawancara sederhana pada mahasiswa/i keperawatan dan awam. Materi yang telah dikumpulkan selanjutnya diolah dalam bentuk presentasi dengan menggunakan Microsoft power point 2007. 
Salah satu manajemen stress dapat dilakukan dengan menggunakan teknikteknik tertentu, maka untuk membantu para penonton mendalami perihal teknikteknik tersebut, maka dibuatlah akun Wordpress.com dengan alamat http:// learnhowtoflywithme.wordpress.com//, yang akan digunakan sebagai sumber informasi bantuan. Selanjutnya adalah membuat akun Youtube.com dengan alamat http://nersmary0145.youtube.com sebagai persiapan untuk proses pendistribusian.

Selanjutnya adalah proses pengambilan Video yang berhubungan dengan materi, yaitu dari Youtube.Com dengan menggunakan situs Keepvid.com. Video yang digunakan adalah dari akun Mischellephan.youtube. com dengan judul video "How tha stress", Trailermovie.youtube.com dengan judul video "Breaking down part 1". Video-video ini akan digunakan sebagai pelengkap materi yang akan di oleh menjadi frameframe tertentu.

Langkah selanjutnya adalah mendownload lagu klasik sebagai backroundmusic frame dengan menggunakan aplikasi TubeMate di Youtube.com di Handphone Samsung Core 2 yang selanjutnya diubah menjadi format Mp3 dengan menggunakan Mp3 video converter di perangkat Handphone yang sama. File yang telah di ubah, lalu dipindahkan ke Asus white PC Notebook tipe 2900. Music yang diambil adalah jenis instrumental dari Kenny $G$ dengan Titanic dari situs kennyg.youtube.com, dan soundtrack ost Full House. Musik-musik ini dipilih karena nada-nadanya yang lembut dan dinilai sesuai dengan materi yang akan di sampaikan.

Setelah proses tersebut di atas selesai, selanjutnya adalah merekam video dengan menggunakan kamera pocket Samsung ES70. Proses perekaman dilakukan dibeberapa tempat seperti di halaman belakang gedung Biomedik Fakultas Kedokteran Universitas Brawijaya (FKUB), Taman belakang gedung FKUB, Lantai satu gedung FKUB, dan rumah. Variasi tempat ini dilakukan untuk mendukung materi yang ada. Taman belakang gedung FKUB dinilai asri, sejuk dan tenang, sangat cocok untuk melakukan pengambilan gambar terkait dengan materi yang berhubungan dengan
PMR (Progressif muscle relaxation) dan Hipnosis lima jari. Hasil pengumpulan materi-materi dikumpulkan dan disimpan di tempat yang sesuai sehingga terhindar dari hal-hal yang tidak diinginkan.

4. Pembuatan

Proses pembuatan dimulai dengan menyatukan materi yang sudah dikumpulkan dengan menggunakan aplikasi Camtasia studio 8.4 sesuai dengan sistem pakar yang sudah dirancang sebelumnya. Proses pembuatan video dibagi menjadi tiga bagian yaitu bagian pembukaan, isi dan penutup. Proses pembuatan dilakukan selama kurang lebih 2 hari.

Selanjutnya adalah membuat transkrip dengan menggunakan MS. Word 2007, selanjutnya di cetak. Transkrip akan berguna dalam proses perekaman suara atau narasi video. Dalam proses perekaman video, Suara hasil perekaman video asli dan video hasil unduhan dihilangkan, diganti dengan perekaman suara dengan mode Voice Naration pada aplikasi Camtasia studio 8.4 dengan bantuan headphone Samsung core 2.

5. Pengujian

Pengujian dilakukan dengan bantuan Mahasiswa/i pascasarjana keperawatan FKUB dan dosen pakar ilmu komputer di FKUB.

6. Pendistribusian

Pendistribusian media pembelajaran dilakukan pada mahasiswa/i perawat, perawat dan orang awam dengan memanfaatkan media sosial seperti Facebook.com,Youtube.com, Wordpress. com dan blogspot.com. Sedangkan Evaluasi pengembangan produk media pembelajaran dilakukan dengan mengambil masukanmasukan dari para komentator pada saat proses pendistribusian dilakukan. Proses pendistribusian dilakukan dalam beberapa waktu tertentu.

\section{HASIL}

Pengolahan media pembelajaran berbasis audio-visual ini dimulai dengan menentukan konsep. Keputusan dijatuhkan pada pengolahan media pembelajaran untuk manajemen stress. Selanjutnya melakukan Perancangan media 
pembelajaran dengan menggunakan sistem pakar. Sistem pakar yang dirancang untuk menghasilkan media pembelajaran berbasis audio visual digambarkan sebagai berikut:

Setelah sistem pakar dikerjakan, dilakukan pengumpulan materi dan pemilahannya. Bagi materi yang memanfaatkan MS. PPT 2007, dilakukan pengolahan terlebih dahulu dalam program MS. PPT 2007 selanjutnya ditambahkan animasi, transisi dan mengubah template agar menjadi lebih menarik. Selanjutnya direkam menggunakan Camtasia studio 8.4 dengan mode record from powerpoint.

Mendownload lagu klasik sebagai backround music frame dilakukan dengan menggunakan aplikasi TubeMate di Youtube. com dengan menggunakan Handphone Samsung Core 2 lalu mengubahnya menjadi format Mp3 dengan menggunakan Mp3 video converter di perangkat Handphone yang sama lalu dipindahkan ke Asus white PC Notebook tipe 2900. Music yang diambil adalah jenis instrumental dari Kenny G dengan Titanic dari situs kennyg.youtube.com, dan soundtrack ost Full House. Sedangkan sebagai tambahan, video lain diambil dari Youtube.Com dengan menggunakan situs Keepvid.com. Video yang digunakan adalah dari akun Mischelle phan. youtube.com dengan judul video "How tha stress", Trailermovie.youtube.com dengan judul video "Breaking down part 1", proses pengambilan video dilakukan langsung dengan memilih format Mp4 sehingga mudah terbaca di aplikasi Camtasia studio 8.4. Materi-materi yang sudah terkumpul selanjutnya langsung di import ke dalam Camtasia Studio 8.4 dan akan secara otomatis dikelompokkan oleh program.

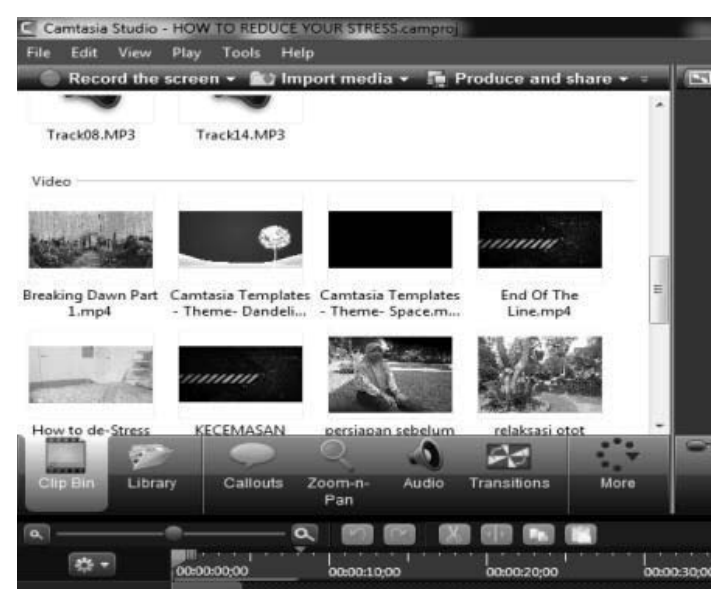

Gambar 2. Hasil import media berupa video, musik dalam program Camtasia studio 8.4 .

Proses selanjutnya adalah pembuatan media pembelajaran. Proses ini dilakukan dengan menggunakan sistem pakar sebagai panduan pengolahan produk. Pengolahan produk menggunakan bantuan hardware dan software. Hardware yang digunakan adalah Notebook PC Asus White tipe 2900, headphone samsung core 2, kamera pocket

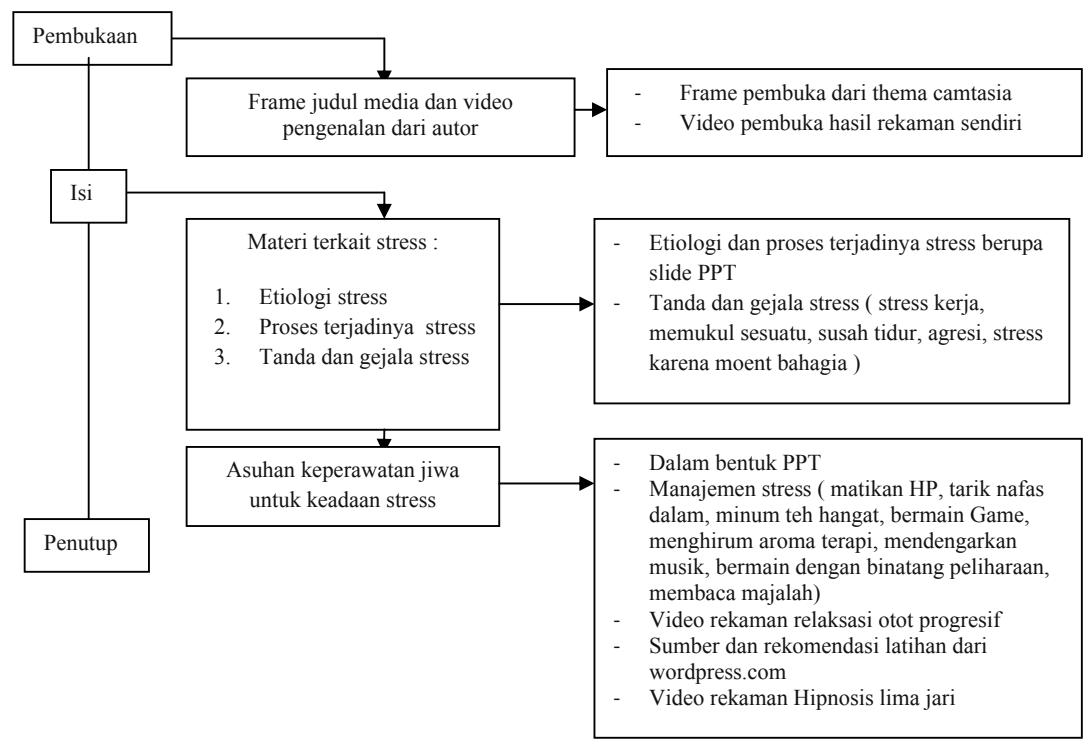

Gambar 1. Sistem pakar media pembelajaran audio-visual manajemen stres. 
Samsung ES70 dan handphone Samsung Core 2. Sedangkan software yang digunakan adalah Camtasia studio 8.4, MS. PPT 2007, tubemate, $\mathrm{Mp} 3$ video converter dan Gadget Youtube ${ }^{\mathrm{Tm}}$, wordpress ${ }^{\mathrm{tm}}$.

Proses untuk membuat "pembukaan" pada media digunakan dengan menggabungkan frame tema video yang diunduh dari youtube ${ }^{\mathrm{Tm}}$ dengan alamat camtasiatheme.youtube. com, tema selanjutnya digabungkan dengan music yang sudah diunduh sebelumnya (ost. Full house). Selanjutnya digabungkan dengan video hasil rekaman sebelumnya sebagai video perkenalan. Selanjutnya adalah masuk pada tahap isi atau inti, yaitu dengan memperkenalkan hal-hal yang terkait dengan etiologi, proses terjadi dan tanda serta gejala stress dalam bentuk MS. PPT 2007. Selama proses penggabungan frame dilakukan pemotongan dan pembuangan dengan memanfaatkan alat split dan delete yang sudah disediakan oleh Camtasia studio 8.4.

Suara di dalam video ini direkam secara terpisah. Proses perekaman dilakukan dengan menggunakan bantuan headphone samsung core 2 dan suasana yang tenang untuk meminimalisir gangguan lalu merekam suara dengan menekan record voice di camtasia studio 8.4. Perekaman juga dilakukan dengan bantuan transkrip yang telah disusun sebelumnya. Suara yang dihasilkan selanjutnya di atur keras dan lembutnya dengan menggunakan tools audio di dalam program aplikasi. Suara hasil perekaman digabungkan dengan suara musik yang selanjutnya di atur agar komposisinya seimbang dan dapat didengarkan dengan jelas dan jernih.

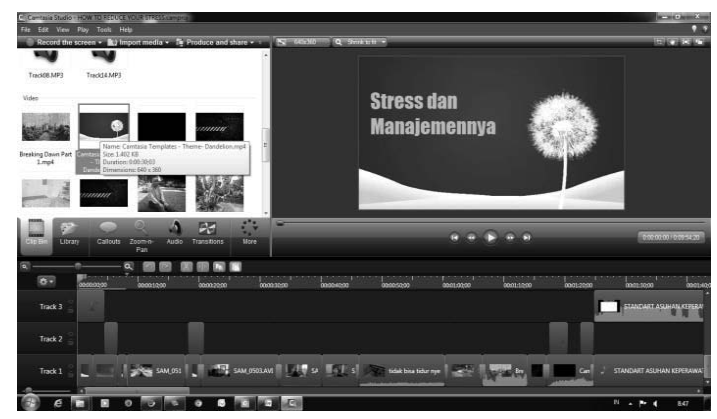

Gambar 3. Proses penggabungan frame-frame di aplikasi Camtasia Studio 8.4.
Proses terakhir adalah melakukan produksi dan pendistribusian. Proses ini dilakukan dengan memanfaatkan tools produce and share pada aplikasi camtasia studio 8.4, selanjutnya memilih format yang diinginkan untuk di produksi. Untuk kapasitas sedang, dipilihlah Mp4 dengan kualitas 480q. Proses produksi dilakukan secara offline sehingga video hasil dapat di upload secara terpisah. Proses selanjutnya adalah pengujian dan pendistribusian. Pengujian dilakukan langsung oleh dosen pakar ilmu komputer selanjutnya adalah dari mahasiswa/i program masteral keperawatan. Setelah dinyatakan layak, video baru di unggah di media sosial untuk dinilai oleh mahasiswa/i keperawatan, perawat dan masyarakat awam. Video diunggah ke alamat, http://mariaayu10@Facebook.com/ ,http://nersmary0145@Youtube.com/,Http:// learnhowtoflywihme@wordpress.com/dan http://nersmary0145@blogspot.com.

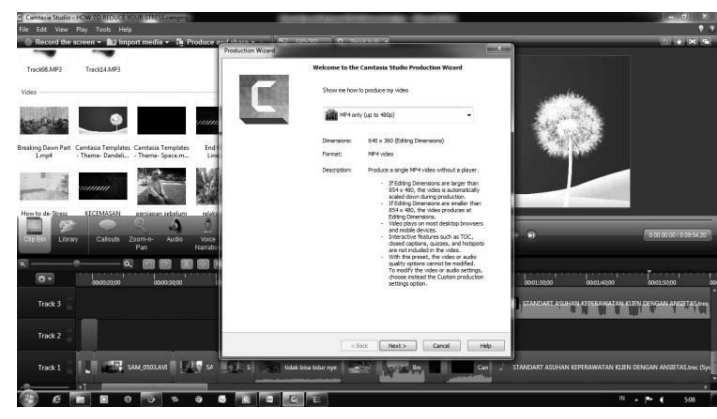

Gambar 4. Proses produksi frame-frame menjadi video.

\section{PEMBAHASAN}

Media diartikan sebagai alat yang berfungsi menyampaikan pesan. Sedangkan pembelajaran adalah sebuah proses komunikasi antara pembelajar, pengajar dan bahan ajar. Sehingga media pembelajaran dapat diartikan sebagai alat yang berfungsi untuk menyampaikan pesan pembelajaran. Media pembelajaran yang baik dapat meningkatkan semangat belajar yang menggunakannya (Binanto, 2010). Pengembangan rancangan media pembelajaran ini memiliki tujuan agar dapat mengembangkan sebuah media pembelajaran dengan basis audiovisual 
yang juga menarik dan dapat mentransfer informasi dengan sederhana, mudah dan menyenangkan.

Produk yang dihasilkan dalam design pembelajaran ini adalah sebuah media pembelajaran untuk mata pelajaran asuhan keperawatan jiwa dengan topik manajemen stress. Produk video pembelajaran ini berbentuk audio visual dengan format $\mathrm{Mp} 4$ durasi 9:54 menit. Video disebarkan melalui

beberapa media sosial dan berhasil mendapatkan beberapa komentar untuk perbaikan dan pengembangan media.

Hasil evaluasi dari Facebook.com menunjukkan hasil 24 kali dilihat, disukai oleh 22 orang, dibagi oleh 2 orang dan diberi komentar oleh lebih dari 10 orang sejak di upload pada tanggal 29 desember 2014 hingga 9 hari selanjutnya yaitu pada tanggal 7 Januari 2015. Komentar yang diberikan memiliki variasi, tapi secara keseluruhan pengunjung menyetujui media pembelajaran ini dirancang untuk menambah variasi dalam mengajarkan mata kuliah. Harapannya media ini, dapat dikembangkan lagi dan terus menerus seperti yang disampaikan oleh pemberi komentar dari akun Annatasia Puji Winata (Seorang mahasiswi keperawatan). Serupa dengan hal tersebut, pemilik akun Ary (seorang perawat ICU) juga memberikan komentar positif bahkan meminta untuk diajarkan. Selain itu pemilik akun Masdiani Ineh Winny juga memberikan komenter positif dan meminta ijin share.

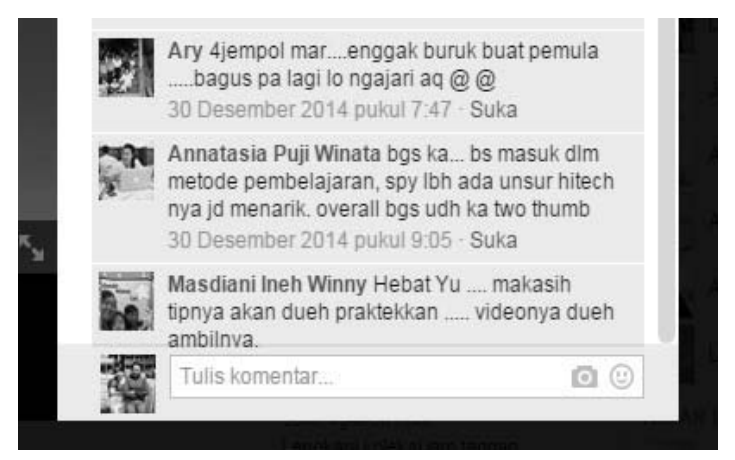

Gambar 5. Komentar-komentar yang diberikan oleh pengunjung untuk pengembangan media pembelajaran.
Komentar positif yang diberikan menunjukkan bahwa media pembelajaran ini layak untuk digunakan dan diterima oleh masyarakat. Menarik bahwa beberapa pengunjung juga meminta diajarkan mengenai media pembelajaran ini. Hal ini menunjukkan bahwa media ini menarik sehingga mereka ingin mempelajarinya lebih dalam terkait dengan proses pengolahan hingga penerbitan sebagai produk. Menanggapi fenomena ini, Townsend (2011) menuliskan bahwa Manusia memang cenderung untuk merasa penasaran dengan hal baru yang mereka lihat dan temukan. Ini merupakan insting yang sudah sejak lama ada dan bermanfaat untuk mengenal dan menilai apakah hal ini berbahaya atau tidak, bermanfaat atau tidak.

Selanjutnya, beberapa komentar terkait dengan isi materi yang diberikan juga dilontarkan, seperti oleh Ali Sodikin Sodikin yang menyoroti proses terjadinya Stress hingga menghasilkan tanda dan gejala yang perlu diperjelas lagi.

Pemilik akun Ali Sodikin adalah seorang praktisi keperawatan jiwa. Sorotan ditujukan langsung pada isi materi terkait dengan proses terjadinya stres dan responnya. Hampir bersamaan pula, pemilik akun Immaculata Osse juga menyarankan untuk mengenalkan terlebih dahulu sumber stress baru selanjutnya diikuti dengan pengenalan langkah-langkah mereduksi stress itu sendiri. Komentar ini berkaitan dengan isi dari video yang masih menitikberatkan pada materi inti dari video yang ingin disampaikan. Memang, sejak awal penyusun konsep, telah disepakati untuk menyederhanakan media pembelajaran yang nantinya akan diberikan kepada mahasiswa/i keperawatan, perawat bahkan kepada masyarakat umum. Sehingga dalam penyusunannya, tidak dilakukan secara mendetail dengan asumsi agar tidak menimbulkan kebingungan. Penjelasan hanya diberikan secara sederhana dan berusaha memunculkan topik-topik yang langsung dapat dilihat, dirasakan dan dipraktikkan.

Komentar lainnya datang dari pemilik akun Ners Yoully, isi komentarnya berisi saran 


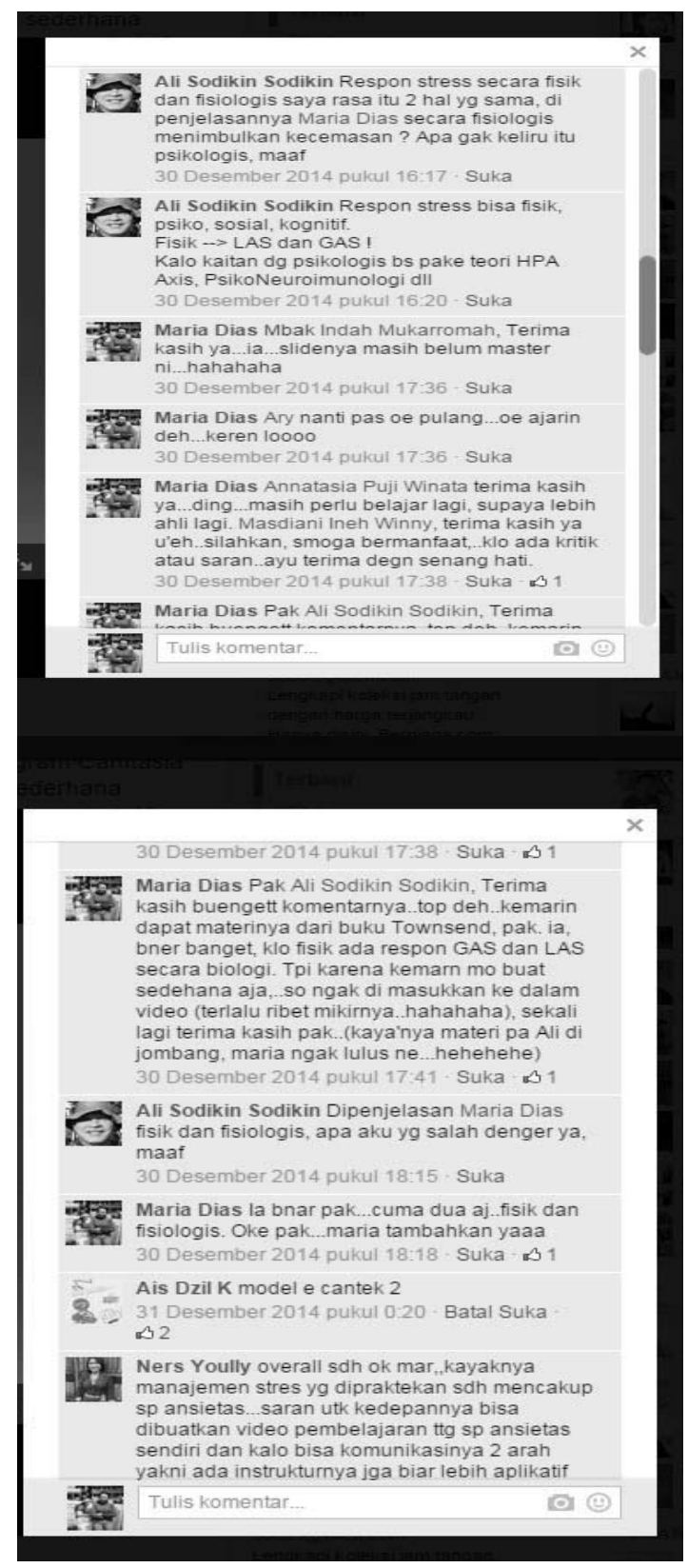

Gambar 6. Komenter pengunjung media sosial Facebook.

untuk melakukan komunikasi interaktif di dalam video yang ditampilkan (komunikasi dua arah) antara model dan pemberi instruktur serta pemisahan antara stress dan ansietas yang ditampilkan di dalam media pembelajaran ini. Pemilik akun NersYoully ini nampaknya tertarik pada model yang digunakan di dalam media pembelajaran ini. Maksud dari pengomentar setelah ditanyakan lebih lanjut adalah pada pengajaran teknik PMR dan hipnosis lima jari. Memang dalam penyusunan konsep dan pengumpulan materi, diputuskan untuk menggunakan model tunggal untuk frame ini (tidak melibatkan interaksi dengan model yang lainnya dalam video). Alasannya adalah karena hal ini dirasa tidak perlu karena konsep yang ingin ditonjolkan di sini adalah teknik. Lalu, perlu diketahui bahwa pengambilan gambar/video dan instruktur PMR dan hipnotis lima jari dilakukan secara bersamaan oleh pengembang produk sendiri. Hal ini mungkin untuk dilakukan, seperti yang pernah dilakukan oleh Hermaningsih and Nargis (2010) dalam penelitiannya.

Selanjutnya adalah dari akun Youtube, sejak di upload pada 31 desember 2014 hingga tanggal 7 Januari 2015 didapatkan video sudah di tonton oleh 8 orang dan disukai oleh 3 orang dan diberi komentar oleh dua orang. Isi komenter kurang lebih sama dengan komentar di media facebook.com. selanjutnya adalah di wordpress.com, ditemukan hasil disukai oleh 2 blogger, dan diberikan satu komentar oleh pemilik akun Linda yakni terkait dengan kejelasan suara media pembelajaran. Untuk akun blogger.com tidak ditemukan komentar apa-apa.

Komentar dari pemilik akun Linda Yani memberikan nilai positif terhadap media pembelajaran ini. Hal ini menunjukkan bahwa hardware yang digunakan di dalam proyek pengembangan media pembelajaran ini sudah tepat. Apalagi yang berhubungan dengan proses pengambilan suara. Memang, dalam perekaman suara, dapat digunakan media-media lain yang lebih canggih, tapi untuk sejauh ini perekaman suara dengan headphone samsung core 2 dapat menjadi salah satu pilihan. Sebagai tambahan, untuk dapat menghasilkan suara yang baik diperlukan suasana yang tenang dan nyaman. Headphone lain sangat disarankan untuk diuji penggunaannya, pengujian dapat dilakukan dengan menghubungkan headphone dengan komputer/laptop/notebook lalu dilakukan test uji perekaman.

Selama proses pembuatan media pembelajaran ini, ditemukan beberapa kesulitan diantaranya adalah mengenai installing windows 2010 yang gagal dilakukan, padahal sebelumnya rencana untuk presentasi, akan digunakan MS. PPT 2010. Sebagai saran, 
rancangan media pembelajaran ini akan lebih baik lagi jika menggunakan MS. PPT 2010 sebagai program untuk membuat presentasi dengan alasan variasi animasi, transisi dan efek-efek presentasinya lebih bervariasi. Selanjutnya pengembang selanjutnya dapat mengurangi pemborosan langkah kerja yang dilakukan untuk melakukan pengunduh-an materi berupa musik. Tanpa harus menggunakan Tubemate dan mp3 Media converter, aplikasi Keepvid.com sesungguhnya dapat mengunduh materi musik berupa MP3 dengan lebih cepat.

Proses promosi media pembelajaran ini pun masih perlu ditingkatkan lagi. Promosi dapat dilakukan dengan menggunakan media-media social dan bahkan tatap muka dengan pengembang media. Tujuannya agar media pembelajaran ini menuai saran dan kritik yang berguna untuk pengembangan media selanjutnya dan tentu saja bermanfaat bagi pengembangan ilmu pengetahuan keperawatan.

\section{SIMPULAN}

Hasil perancangan berhasil membuat media pembelajaran berbasis audiovisual dan mendapatkan respon yang bervariasi dari masyarakat. Media pembelajaran ini layak digunakan untuk membantu proses pembelajaran di kelas.

\section{SARAN}

Untuk studi selanjutnya, pengembang dapat menggunakan rancangan ini sebagai dasar pengembangan media pembelajaran berbasis audio-visual dengan menambahkan beberapa komponen materi seperti yang telah disarankan oleh para komentator-komentator sebelumnya.

\section{KEPUSTAKAAN}

Billings, D. M, \& Halstead, J. A. 2005. Teaching in nursing: A guide for faculty. Philadelphia: W.B. Saunders.

Binanto, W. 2010. Multimedia digital: dasar Teori dan pengembangan Yogyakarta Andi.

Brunero, S, Jeon, Y.H, \& Foster, K. 2012. Mental Health education programmes for Generalist Helath profesionals: An integrative review. International journal of Mental helath nurisng 1, 428-444.

Hansen, M, \& Erdley, S. 2009. Youtube and Other Web 2.O Aplication for Nursing Education Online Journal of Nursing Informatics, 13(3), 1-20.

Hermaningsih, S, \& Nargis. 2010. Penggunaan media bantu audio visul dan leaflet terhadap perubahan perilaku perawatan diri pra remaja di Sekollah menengah pertama kecamatan buahbatu kota Bandung Politeknik Kesehatan Jurusan Keperawatan Bandung.

Lamont, S, \& Brunero, S. 2012. 'eSimulation' part 1: Development of an interactive multimedia mental health education program for generalist nurses. The Australian Journal of Nursing Practice, Scholarship and Research Article in Press.

Mubin, M.N. 2013. Perancangan media pembelajaran interaktif sistem skeletal pada mata kuliah dasar keperawatan I. Jurnal sistem Skeletal 0.1, 1-11.

Townsend, M.C. 2011. Essesntial of Psychiatric Mental Helath Nursing Philadephia: Davis Company. 